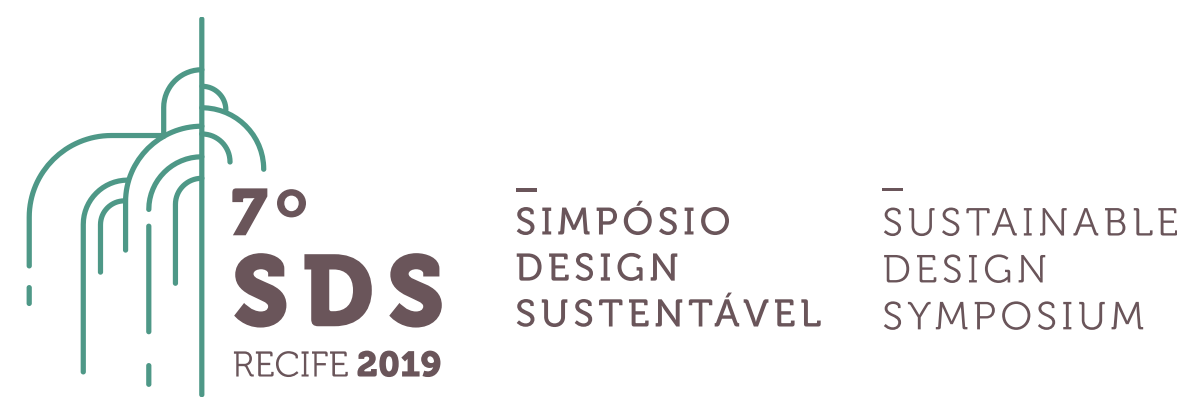

\title{
Sustentabilidade vem de berço: aceitação de um serviço ecoeficiente para a composição do quarto infantil
}

\author{
Julia Pereira Soares ${ }^{1}$, Alfredo Jefferson de Oliveira ${ }^{2}$, Rita Maria de Souza Couto ${ }^{3}$ \\ 1PUC-Rio, Departamento de Artes e Design, juliaecodesign@gmail.com \\ ${ }^{2}$ PUC-Rio, Departamento de Artes e Design, afferson@puc-rio.br \\ ${ }^{3}$ PUC-Rio, Departamento de Artes e Design, ricouto@puc-rio.br
}

\begin{abstract}
Resumo. Este artigo apresenta os resultados de uma investigação sobre a aceitação de um serviço ecoeficiente hipotético para o reuso do mobiliário do quarto infantil. O mobiliário do quarto infantil tem uso de curta duração e passa por constante renovação para acompanhar o desenvolvimento do bebê e da criança. Sugere-se então, um serviço ecoeficiente como solução para reduzir os impactos deste consumo de móveis. Serviços ecoeficientes são considerados como inovações na economia, que por meio de ciclos de reuso, podem tornar o sistema de produção e consumo mais sustentável. Estes sistemas baseiam-se na transferência da propriedade do consumidor para o produtor, o qual será responsável por manter a ecoeficiência de produção e pela extensão da vida útil do produto. Pesquisas afirmam, no entanto, que a aceitação de serviços desprovidos de propriedade, pelo consumidor, enfrenta barreiras e está sujeita à influência de diversos fatores. A partir da literatura e de questionários aplicados ao consumidor, esta pesquisa identificou os fatores influenciadores e distinguiuos em fatores materiais e fatores psicossociais. Dentre os fatores materiais mais relevantes encontrou-se: a relação de custo-benefício, a adequação do serviço ao uso e a responsabilidade pelo destino do produto. Identificou-se como fatores psicossociais mais relevantes: o valor simbólico do novo, e o valor da sustentabilidade. Concluiu-se, a partir da análise dos fatores apontados pelos respondentes, que há uma atitude positiva em relação aos serviços ecoeficientes.
\end{abstract}

Palavras-chave. Serviços ecoeficientes; Aceitação pública; reuso; mobiliário; quarto infantil.

\section{Introdução}

Ao longo dos últimos 60 anos a humanidade vem se tornando cada vez mais consciente da crise socioambiental e dos limites do planeta. Literalmente, é sentido cada vez mais na pele os efeitos das mudanças climáticas, da poluição atmosférica, do acúmulo de resíduos e da falta de recursos básicos para o sustento da vida humana. Desde a década de 1960, com o surgimento do movimento ambientalista, diversos setores da sociedade vêm reivindicando uma mudança no 
atual modelo de vida, produção e consumo. Neste período de tempo, a sociedade civil, políticos, ambientalistas, entre outros, se reuniram para pensar em soluções capazes de reverter os efeitos da crise socioambiental. Foram definidas agendas, normas ambientais, e cunhou-se o conceito de desenvolvimento sustentável e de sustentabilidade.

Mesmo estando consciente desta crise em todo este tempo, a humanidade está longe de ter atingido o modelo de desenvolvimento que se propôs para sustentar a população atual e as futuras, dentro de padrões mínimos de qualidade de vida.

Autores como Guattari (1990) e Manzini (2008) afirmam que somente uma descontinuidade sistêmica, uma ruptura com o modelo atual de produção e consumo, pode levar de fato a uma sociedade sustentável. Esta descontinuidade implica numa demanda por um bemestar no mundo profundamente diferente do contexto atual.

As expectativas de bem-estar da sociedade contemporânea, principalmente a ocidental, são fundamentadas no prazer que se associa à obtenção de bens materiais para consumo individual e próprio. Os produtos de propriedade individual ganharam tamanha importância para a nossa sociedade, que atribuímos a eles - para além das necessidades que cada indivíduo considera como "básicas" - a função de representar a nossa imagem de felicidade, identidade e status. O consumo de produtos sacia desejos subjetivos. E, para uma vasta quantidade de produtos, o desejo pela sua aquisição é tão fugaz quanto o seu descarte e desejo por outro modelo mais atualizado ou novo. Este modelo de bem-estar, estimulado pelo sistema capitalista e linear de produção e consumo, fundou a sociedade de hiperconsumo ${ }^{a}$ que, somada ao exponencial crescimento populacional e à rápida depreciação dos produtos - cada vez mais descartáveis e de vida curta - vem degradando intensivamente os ambientes naturais e urbanos, através do esgotamento dos recursos naturais e seu descarte inadequado.

A ruptura necessária para modificar este modelo depende de uma mudança por parte não só dos que produzem, mas também dos que consomem.

\section{Serviços Ecoeficientes}

Acompanha-se atualmente, o surgimento de várias iniciativas que têm o reuso e o compartilhamento como solução de consumo. Estas iniciativas visam otimizar o uso de produtos com vistas à redução da extração de novos recursos e do desperdício. Dentro desta nova perspectiva de consumo, conhecida hoje como economia circular, os bens materiais, por meio de ciclos de reuso, podem ter seu uso intensificado, sua vida prolongada e sua fabricação reduzida. Desta forma, o valor que se atribui à venda do produto é transferido para a sua utilização ou desempenho. Nesta 'Economia do Desempenho' (Perfomance Economy, STAHEL, 2010), a propriedade e responsabilidade sobre o produto passa a ser do fabricante ou fornecedor e não do consumidor. Essa transferência de responsabilidade pelo produto estimula o produtor, agora proprietário, a produzir bens mais duráveis e que consomem menos recursos materiais e energéticos, já que este passa a ter o controle sobre todo o ciclo de vida de seus produtos. 0 consumidor não detém a propriedade dos bens consumidos, tendo acesso somente ao uso ou à função dos produtos.

A partir do conceito de economia circular, uma diversidade de pesquisas vem descrevendo sistemas e modelos de negócios, que combinam produtos e serviços ou que substituem a venda

\footnotetext{
${ }^{\text {a }}$ A expressão é usada de acordo com Botsman e Rogers (2011). Segundo os autores, hiperconsumismo é a tendência à “aquisição interminável de mais coisas em quantidades cada vez maiores". Este consumo excessivo - que explodiu na década de 1950 nos Estados Unidos - tem como estímulo forças manipuladoras discriminadas como: o poder de persuasão da publicidade e as formas facilitadoras de se pagar pelos produtos (a cultura dos cartões de crédito de se "comprar agora e pagar depois") (BOTSMAN e ROGERS, 2011, p.18).
} 
de produtos pela venda de serviços, como uma abordagem promissora para se alcançar um consumo sustentável. Assim, para estes modelos, têm sido utilizados diversos termos como: Sistema Produto-Serviço, de sigla em inglês PSS, (VEZZOLI et al., 2018; TUKKER, 2004; MONT, 2002); Serviços Ecoeficientes (MEIJKAMP, 1998; SCHRADER, 1999; BREZET et al., 2001); Ecoserviços (BEHRENDT et al., 2003); e Consumo baseado no acesso (ABC) (BARDHI e ECKHARDT, 2012). Todos eles se baseiam no conceito de que: substituir a venda dos produtos pela venda de seu uso ou funcionamento, com a transferência da propriedade para o produtor, é uma maneira de reduzir o volume e a velocidade do fluxo material na economia, desvinculando o impacto ambiental negativo do crescimento econômico, enquanto satisfaz demandas particulares do consumidor.

Muitos autores classificam os tipos de serviços, distinguindo-os em três categorias principais quanto a sua forma de funcionamento e nível de ecoeficiência: serviço orientado ao produto; serviço orientado ao uso; e serviço orientado ao resultado. (VEZZOLI et al., 2018; TUKKER, 2004; BEHRENDT et al., 2003; SCHRADER, 1999) (Quadro 1).

O fator de sustentabilidade do sistema produto-serviço é inerente à forma de funcionamento e design do sistema (VEZZOLI et al., 2018; MONT, 2002). Segundo Tukker (2004), quanto mais se substitui o produto por serviços, maior a ecoeficiência do sistema. Logo, para este autor, os serviços orientados ao produto são os de menor valor para a sustentabilidade. Behrendt et al. (2003), por sua vez, não consideram sistemas de serviços orientados ao produto como Ecoserviços. Para Schrader (1999) os serviços orientados ao produto não modificam o atual comportamento de consumo, logo não têm relevância na discussão sobre a aceitação pelo consumidor. Por estas razões, esta pesquisa considera como serviços ecoeficientes somente os serviços que substituem a propriedade (em cinza, no quadro 1).

Quadro 1 - Categorias de serviços e suas características

\begin{tabular}{|c|c|c|}
\hline Categorias de Serviços & Tipos de serviços & $\begin{array}{l}\text { Quanto à transferência da } \\
\text { propriedade }\end{array}$ \\
\hline 1. Serviço orientado ao produto & Manutenção, atualização, consultoria & $\begin{array}{l}\text { Serviços que complementam a } \\
\text { propriedade }\end{array}$ \\
\hline 2. Serviço orientado ao uso & $\begin{array}{l}\text { Eco-aluguel (uso individual) } \\
\text { Eco-compartilhamento (uso conjunto) }\end{array}$ & \multirow{2}{*}{$\begin{array}{l}\text { Serviços que substituem a } \\
\text { propriedade }\end{array}$} \\
\hline 3. Serviço orientado ao resultado & & \\
\hline
\end{tabular}

Fonte: Adaptado de Tukker (2004), Schrader (1999), Behrendt et al. (2003)

Apesar destes negócios se mostrarem vantajosos e serem cada vez mais implementados com sucesso, principalmente, no setor empresarial, o consumo desprovido de propriedade ainda enfrenta algumas barreiras para sua aceitação no mercado consumidor privado.

\section{Sustentabilidade na composição do quarto infantil}

Em sua motivação original, este artigo nasceu da percepção de que a atuação do designer de interiores pode ser, em muitos casos, prejudicial ao ambiente, uma vez que demanda materiais e processos que exploram os recursos naturais, mesmo os renováveis que não se renovam no mesmo ritmo de seu consumo. Logo, alimenta-se um sistema de consumo insustentável. 
Simultaneamente ao hiperconsumo, tem-se uma sobreprodução de bens materiais que não é consumida e se torna desperdício, aumentando ainda mais a degradação ambiental.

Pode-se perceber que, em grande parte das vezes, o design e as reformas de ambientes residenciais acontecem por que há a percepção de que algo se torna obsoleto: objetos quebram, perdem a função, se desatualizam ou perdem significado. A partir da percepção de que o quarto infantil é um cômodo que se renova com grande frequência, em função do crescimento e desenvolvimento da criança, este se tornou o foco da busca pela sustentabilidade no design de interiores residencial.

A mobília do quarto infantil, do bebê à criança, tem um uso de curta duração. Isso porque, em nossa cultura ocidental, desenvolvemos a necessidade de adaptar o mobiliário às dimensões das crianças e às ideias que construímos em torno do conceito de infância. Isso levou à produção de uma estética especializada para o design de móveis infantis e à necessidade constante de reformar o quarto das crianças para acompanhar seu desenvolvimento cognitivo e crescimento físico. Isto contribui para a obsolescência psicológica e funcional do projeto, causando impactos não somente ao ambiente, mas também econômicos para o consumidor.

Entre as possíveis estratégias de redução dos impactos ambientais negativos das reformas e renovação de mobiliário, destaca-se o design de um sistema de serviço ecoeficiente como opção que visa a sustentabilidade do projeto de composição do quarto infantil. Trata-se de um ecoaluguel (Quadro 1) de mobiliário destinado ao quarto infantil. A diferença para um aluguel tradicional está no design do sistema, que deve ser projetado conforme critérios de ecoeficiência e sustentabilidade (VEZZOLI et al., 2018).

Para o propósito deste estudo, definiu-se o tipo de serviço estudado como Serviço ecoeficiente orientado ao uso individual. Pois, o termo "ecoeficiente", além de evidenciar a vertente ecológica do sistema, é de mais fácil compreensão do que o termo PSS, para o público que não participa destas discussões acadêmicas. O serviço é "orientado ao uso individual", pela lógica de uso do mobiliário infantil. Diferentemente dos serviços de compartilhamento, cujo uso é conjunto, o tempo de uso dos móveis para o quarto infantil é mais longo e intenso, justificando seu uso individual por determinado período de tempo.

Ainda que esta estratégia não seja ecoefetiva em sua totalidade, ela é um passo para uma mudança de comportamento de consumo que pode reorientar os objetivos da produção dos bens materiais. É um caminho a ser trilhado, que parte de um consumo ecoeficiente em direção a um consumo suficiente, o qual "significa a revisão dos atributos de satisfação, estilo de vida e hábitos de consumo, buscando aproximar o consumo das necessidades reais de cada indivíduo e dos limites de resiliência do planeta terra (...)" (SANTOS, 2013, p.28).

\subsection{Sobre o quarto infantil}

Em pesquisa às principais lojas para mobiliário infantil da cidade do Rio de Janeiro, foi possível obter dados sobre o mobiliário mais tipicamente utilizado nos quartos infantis - desde o bebê ao pré-adolescente. O levantamento feito encontra-se no quadro 2 .

Quadro 2 - Tipologia de mobiliário utilizado na composição do quarto infantil

\begin{tabular}{lll}
\hline Móveis de repouso & Móveis de guarda & Móveis de apoio e assento \\
\hline $\begin{array}{l}\text { Moisés, miniberço, berço, berço } \\
\text { multifuncional, minicama, minicama } \\
\text { montessoriana, bicama, beliche, }\end{array}$ & $\begin{array}{l}\text { comum. } \\
\text { cama-brinquedo, cama temática. }\end{array}$ & $\begin{array}{l}\text { Poltrona de amamentação, mesinha } \\
\text { e cadeirinha, escrivaninha e cadeira. }\end{array}$ \\
\hline
\end{tabular}


Como se observa a partir do levantamento (Quadro 2), o mobiliário destinado ao repouso da criança, em especial, apresenta uma enorme variedade de tipos que variam em função do tamanho da criança, entre outras necessidades percebidas, como a possibilidade de se estender o tempo de uso por meio de soluções multifuncionais. Este levantamento confirma as sucessivas mudanças que se faz, ao menos, ao móvel destinado ao repouso da criança.

O pressuposto de que o mobiliário do quarto infantil é potencialmente elegível para este tipo de serviço parte das seguintes premissas: os móveis infantis, ao atender normas de segurança, costumam ser resistentes e durar muito além do tempo destinado a seu uso; possuem alto valor comercial; são comumente revendidos em mercado de segunda-mão e competem com o mercado do novo (MONT et al., 2006). Culturalmente, o mobiliário do quarto infantil dura pouco tempo e costuma ser todo ou parcialmente substituído. Normalmente, ao serem reconhecidas as novas "necessidades", modificam-se o estilo, a função e a estética dos móveis. Desta forma, os móveis que muitas vezes são adquiridos como conjunto de mesmo estilo estético, são também descartados em conjunto, para se adquirir uma nova composição estética e funcionalmente coerente com os novos desejos.

\subsection{Problema e objetivo}

Pesquisas evidenciam que o consumo baseado no acesso ao uso, e não à propriedade, ainda se depara com alguns fatores que influenciam a sua aceitação pelo consumidor-usuário. (MONT e PLEPYS, 2003; BEHRENDT et al., 2003; SCHRADER, 1999; CATULLI et al., 2013). Os consumidores estão acostumados ao modo de consumo linear, no qual se paga pela propriedade e responsabilidade pelo produto e, consequentemente, pela conveniência de um uso individual e ilimitado e a liberdade sobre o uso que se faz de seus próprios produtos.

Portanto, ao se propor uma estratégia cujo funcionamento depende de uma mudança atitudinal, é necessário que se investigue a propensão da sociedade em aceitar tal proposta. Logo, para compreender a aceitação pública de um sistema de serviço ecoeficiente para a composição do quarto infantil, buscou-se identificar, do ponto de vista do consumidor, os fatores que influenciam positiva ou negativamente a adoção do serviço proposto.

\section{Fatores de influência para a aceitação de serviços ecoeficientes}

Para o consumidor, o consumo desprovido da propriedade pode trazer benefícios ao reduzir os fardos associados à propriedade. Segundo Moeller e Wittkowski (2010), estes "fardos" estariam associados a uma variedade de riscos e responsabilidades, tais como: os riscos relacionados a alterações ou obsolescência do produto; à escolha incorreta na compra de um produto; a responsabilidade pela manutenção e reparo do produto; e o alto custo que o consumidor paga por produtos que poderão ter pouco uso ou utilidade.

No entanto, apesar destes aparentes benefícios da ausência de propriedade, a aceitação do serviço pelo mercado consumidor ainda é lenta se comparada ao mercado entre empresas, onde serviços vêm sendo cada vez mais implementados. Em 2003, a pesquisa de Behrendt et al. (2003) afirmava que a preferência do consumidor por Eco-serviços ainda era bastante reduzida nos países investigados da União Europeia. Já em 2010, Moeller e Wittkowski (2010) observaram um crescente interesse pelo aluguel, também na Europa. Mas ainda hoje, no Brasil, são poucos os casos de design de sistemas produto-serviço efetivamente orientados à ecoeficiência ou à sustentabilidade (SANTOS, 2013), motivo pelo qual se faz difícil avaliar sua aceitação.

Segundo Mont e Plepys (2003), diferente da compra tradicional, o ato de consumir um sistema produto-serviço vai além da decisão entre pagar pela propriedade ou pagar pelo uso. A 
escolha do consumidor diante do ato de consumir um produto passa por um complexo processo de tomada de decisão, além de numerosos outros fatores que influenciam os padrões de consumo. O campo do design de serviços ecoeficientes e PSS voltados para o mercado consumidor privado ainda está em desenvolvimento. Logo, compreender estes fatores influenciadores; a percepção e o comportamento do consumidor; ou como a aceitação por soluções sustentáveis é influenciada, é relevante para se projetar novos sistemas de consumo (MONT e PLEPYS, 2003).

O reduzido número de pesquisas com foco em barreiras à adoção de PSSs ou em sua aceitação pelo consumidor é reflexo da baixa variedade de serviços ecoeficientes existentes para serem testados. A maioria das pesquisas concentra-se em serviços existentes, tais como, compartilhamento de carros e serviços de lavanderia ou serviço pay-per-use de máquinas de lavar.

Neste sentido, a presente pesquisa teve como foco um serviço ecoeficiente hipotético para acessar a opinião do consumidor e compará-la à leitura a respeito dos fatores de influência ao consumo de serviços ecoeficientes. Os autores de base pesquisados, com este objetivo, foram: Schrader (1999); Oliveira (1999); Behrendt et al. (2003); Catulli (2012; 2013); Cherry e Pidgeon (2018).

Tomando como ponto de partida a literatura, foram identificados diversos fatores que influenciam a adoção dos serviços. Um sistema de serviço ecoeficiente, para ser aceito, deve apresentar uma vantagem relativa em relação à propriedade. A apreciação destas vantagens depende, logicamente, das características do produto, do perfil do consumidor e de sua relação com o produto (SCHRADER, 1999). Na presente pesquisa, estes fatores de influência - que podemos chamar também de vantagens ou desvantagens - foram agrupados da seguinte maneira: fatores materiais (ligados às características do produto e do serviço) e fatores psicossociais (ligados a questões subjetivas individuais ou culturais dos consumidores).

Mont e Plepys (2003) colocam que modificar o comportamento e estilo de vida humano é um processo extremamente difícil, de forma que, é potencialmente mais fácil projetar os serviços com a intenção de reduzir os entraves comportamentais. Por esta razão distinguiu-se os fatores nestas duas categorias, levando-se em conta que as influências dos fatores materiais podem ser mais facilmente contornadas ao se projetar o serviço.

\subsection{Fatores materiais}

Diversos fatores estão ligados às características do produto que participa do sistema. 0 preço; a intensidade e o tempo de uso; o espaço de armazenamento que ocupam e a qualidade do produto foram fatores colocados por quase todos os autores pesquisados.

Quando o preço inicial para a compra do produto novo é considerado alto a consideração pelo uso do serviço aumenta, principalmente se existe a percepção de que o tempo de uso do produto será curto e a intensidade de seu uso for baixa (SCHRADER, 1999; BEHRENDT et al., 2003). Também apresentou forte influência, o tamanho do objeto e o espaço que ele ocupa para ser armazenado (BEHRENDT et al., 2003; CATULLI, 2012). Consumidores que possuem pouco espaço em suas residências tendem a valorizar mais os serviços por diminuir este "fardo" da propriedade. Consequentemente, quanto mais estes fatores se inter-relacionam maior é a aceitação do serviço.

A percepção da qualidade do produto que participa do serviço também é considerada pelo consumidor. Este precisa de garantias de que o objeto está em boas condições de uso e segurança, o que se reflete, muitas vezes, na marca do produto. Marcas que são, por experiência do consumidor, reconhecidamente duráveis e apresentam garantias de segurança são preferíveis (CATULLI, 2012). O autor também afirma que é necessário que haja informação suficiente sobre a vida do produto para que haja confiança no serviço.

Outros fatores se relacionam às vantagens ou desvantagens percebidas, ligadas às 
características do serviço. Consumidores temem alguns riscos que podem estar associados a prévias experiências com contratos de aluguel: o medo de não poder arcar com custos até o final do contrato, e o risco de serem surpreendidos com custos adicionais. Alguns consumidores também demonstraram preocupação em danificar o produto, o que os levaria a ter um maior cuidado com o uso, restringindo a liberdade de uso do produto. Outros, em contraposição, afirmaram que a falta da propriedade diminuiria os cuidados com o produto, ampliando a liberdade de uso (CHERRY e PIDGEON, 2018).

Outro fator crucial para a aceitação é a relação de custo-benefício. Consumidores tendem a não conseguir avaliar apropriadamente os custos de um produto ou serviço (CATULLI, 2012), o que gera incertezas. Neste sentido, as conveniências que o serviço pode trazer ou suprimir, ao ser comparado à compra, vão afetar esta avaliação. O consumidor não quer abrir mão da autonomia, flexibilidade e controle associados à propriedade (CHERRY e PIDGEON, 2018). Logo, se o serviço puder suprir estas conveniências como, a disponibilidade de ter o produto sempre à mão quando precisar (o que se reflete também numa economia de tempo), ou a liberdade sobre seu uso, maior será sua aceitação. Também se torna vantajoso para o serviço apresentar uma grande variedade para escolhas, assemelhando-o à compra tradicional.

Outras características que contribuem para a aceitação do serviço é o fornecimento de serviços percebidos como adicionais: a garantia de manutenção e reparo; a possibilidade de atualização; a possibilidade de experimentar para evitar uma compra equivocada (BEHRENDT et al., 2003).

\subsection{Fatores psicossociais}

Apesar de, em diversos sentidos, a provisão do serviço satisfazer as necessidades de uso do consumidor e reduzir os "fardos" associados à propriedade, deve-se considerar que o consumo tradicional baseado na propriedade também satisfaz necessidades menos tangíveis, relacionadas ao envolvimento que as pessoas desenvolvem com produtos (SCHRADER, 1999). A própria condição de ser proprietário inclui outros valores além das demandas básicas de uso, como o valor de status, identificação, distinção, ou a simples satisfação em ser dono. O fato dos objetos que participam do serviço já terem sido utilizados por outros usuários também modifica as relações de uso e afeto com os objetos.

Stahel (2010) afirma que o sucesso deste modelo de consumo no setor entre empresas (B2B) se deve ao caráter instrumental dos produtos utilizados no serviço. Segundo o autor existem duas categorias de produtos: as "ferramentas" (tools) e os "brinquedos" (toys). Quando o que se espera de um produto é unicamente sua funcionalidade ou desempenho, o objeto é considerado uma "ferramenta". Mas já, quando a relação com os produtos passa por critérios emocionais de escolha, estes são considerados "brinquedos". Neste caso, os modismos também terão grande influência sobre as escolhas de consumo. Desta forma, segundo o autor, ao se entender a diferença entre estas duas categorias de produtos torna-se mais fácil conquistar com sucesso o mercado consumidor.

Schrader (1999) também compreende que a importância individual de um produto para o consumidor dita o que pode ser substituído por um serviço ou não. No entanto, o autor coloca que identificar quais objetos são "ferramentas" e quais são "brinquedos" não é tão trivial quanto parece, uma vez que "um mesmo produto pode satisfazer simultaneamente diferentes necessidades e que estas podem variar de acordo com os consumidores ou contextos de uso." (OLIVEIRA, 2000). Um carrinho de bebê, por exemplo, é um objeto que, para alguns usuários, pode ser estritamente funcional. Porém, como identificaram Catulli (2012) e Mont et al. (2006), a natureza do produto (uso com bebês) pode influenciar o valor emocional da relação com este objeto, o que pode dificultar a aceitação de um serviço de reuso. Muitas vezes, para uso do bebê - 
em especial o recém-nascido - o consumidor quer algo que seja novo. O autor, ao investigar os consumidores, identificou que "estavam preocupados não somente com a higiene e boa condição do produto, mas também queriam que eles estivessem 'novos e brilhantes' por que eles querem o melhor para seus bebês." (CATULLI, 2012, p.11).

Este aspecto cultural observado se relaciona com o valor simbólico que se atribui aos objetos novos e a depreciação pelos reutilizados. O conceito de novo apresenta variados significados: o de novidade e modernidade; o de perfeito estado; o de pouco tempo de fabricação ou de uso; e o de intocado (primeiro uso) (OLIVEIRA, 2000). Este último, também conhecido como "valor de virgindade" (STAHEL, 2004 apud OLIVEIRA, 2000), é o que representa a principal barreira cultural, uma vez que os outros significados de "novo" podem ser atendidos pelo serviço de acordo com o seu design. Alguns consumidores se preocupam não somente com a higiene física dos objetos, mas também com uma possível contaminação "energética" (OLIVEIRA, 2000; CATULLI, 2013). Oliveira (2000) coloca que os objetos "virgens" não têm marcas, e que as marcas são vestígios da história dos objetos e seus antigos donos. Por mais que num serviço de reuso, o objeto passe por um processo de reparo ou remanufatura, e apresente o mesmo aspecto de um produto novo, isto não elimina sua "alma" de usado. O que pode ser identificado como uma barreira cultural ao serviço. Inversamente, o valor simbólico dos vestígios se torna positivo quando os antigos usuários são parentes ou pessoas próximas (ou ídolos). Nestas condições os consumidores estão dispostos a compartilhar os equipamentos (CATULLI, 2012).

Os autores também identificam o padrão e estilo de vida como fator de influência à aceitação. Percebe-se um preconceito com o aluguel por estar associado ao estigma social de que é uma "solução para consumidores mais pobres" (CATULLI, 2012). Por este motivo, alguns consumidores não querem ser identificados como usuários de objetos alugados. Neste sentido, a marca aparente no produto também passa a ter papel importante na veiculação da imagem e identidade do consumidor que quer ser visto como pertencente a determinado grupo social. Catulli (2013) revela que alguns consumidores se importam mais com a aparência do que com o fato de não serem donos. A marca do serviço não poderia aparecer nos carrinhos de bebê (objeto investigado), no entanto, a visibilidade de uma marca cara seria desejável. O autor identifica também que existe uma parcela de consumidores, em oposição, que valoriza e adota comportamentos sustentáveis como estilo de vida, e logo, está mais propensa a usar serviços ecoeficientes.

\section{Aceitação do Serviço ecoeficiente para o quarto infantil}

Esta foi uma pesquisa de natureza exploratória e descritiva, que contou com métodos qualitativos e quantitativos, com o objetivo de investigar a aceitação de um serviço ecoeficiente para a composição do quarto infantil. A pesquisa se inspirou em métodos qualitativos utilizados, em pesquisas semelhantes, por Catulli (2012) e Behrendt et al. (1999).

\subsection{Método}

Para acessar a opinião pública sobre o serviço proposto foi elaborado um questionário em ferramenta digital (Google forms), e enviado aos respondentes por meio de aplicativos de mensagens, endereço de e-mail e publicado em redes sociais. Os respondentes não foram identificados, respondendo anonimamente. A pesquisa foi direcionada a um público alvo, composto por mães, pais e/ou responsáveis por crianças que se encontram na faixa de idade entre três e doze anos. Este recorte foi realizado pelo fato de que, no período identificado, o quarto infantil já sofreu reformas ou variações na composição de seu mobiliário.

No início do questionário, apresentou-se o serviço hipotético proposto como um sistema de aluguel orientado ao uso do mobiliário infantil, distinguindo-o do sistema de compra 
tradicional. Em seguida, por meio de quatro perguntas discursivas, pediu-se aos respondentes que expusessem livremente suas opiniões e percepções tanto sobre as vantagens e desvantagens do serviço proposto, quanto do sistema tradicional de consumo baseado na propriedade individual. 0 serviço foi apresentado de forma não tão rigorosamente definida, sendo proposital para que o respondente levantasse espontaneamente seus próprios questionamentos acerca do serviço e fornecesse alternativas, sobre como este serviço poderia funcionar, de forma que ele mesmo considerasse adotá-lo. O questionário teve como objetivo identificar quais fatores dificultam ou facilitam a aceitação e adoção do serviço.

\subsection{Resultados e discussão}

Não foi possível quantificar o número total de questionários enviados, pois estes foram replicados em rede e publicados em grupos. Obteve-se o total de 85 respostas.

\subsubsection{Fardos da Propriedade}

Ao serem indagados sobre as desvantagens da propriedade do mobiliário infantil e do serviço hipotético proposto, $25 \%$ dos respondentes afirmaram não ver desvantagens no serviço e $4 \%$ não percebem desvantagens na propriedade deste mobiliário. As opiniões restantes foram agrupadas por tema e destacadas aqui as mais quantitativamente relevantes. As desvantagens mais percebidas pelos consumidores, em relação à compra do mobiliário infantil, foram: a dificuldade em se desfazer dos móveis; o alto custo para pouco tempo de uso; e o espaço que ocupam.

Segundo 39\% dos consumidores, é difícil passar os móveis adiante após o uso. Revender ou, até mesmo, doar os móveis demanda tempo, custos de frete ou ficar à disposição de compradores. Outros consideram a desvantagem da perda de dinheiro neste processo, por ter que revender mais barato e comprar um móvel novo mais adaptado, "A desvantagem é ter que se desfazer quando não tiver mais utilidade. Acabamos por ficar com o produto porque trocar demanda um gasto grande." (respondente no 24).

Fato que leva à segunda desvantagem mais comentada: o alto investimento em um mobiliário que vai durar pouco tempo, corroborando o "fardo" colocado por Moeller e Wittkowski (2010). Além da velocidade em que se tornam obsoletos, a dificuldade em se desfazer com prontidão faz com que os objetos ocupem espaço por mais tempo do que o desejado, "Objetos ficam encalhados depois que o bebê cresce e falta espaço para guardar os objetos posteriormente." (respondente no 53).

\subsubsection{Vantagens e desvantagens do serviço ecoeficiente}

Estas características da compra tradicional do mobiliário infantil, ao serem percebidas como "fardos", tornam-se vantagens relativas para o serviço. O quadro 3 apresenta todas as vantagens e desvantagens, apontadas pelos consumidores, que podem influenciar positiva e/ou negativamente o serviço.

Quadro 3 - Vantagens e desvantagens do serviço ecoeficiente para o mobiliário infantil

\begin{tabular}{ll}
\hline Vantagens do serviço ecoeficiente & Desvantagens do serviço ecoeficiente \\
\hline *Adequação ao uso, flexibilidade & *Não poder manter na familia, doar ou revender \\
*Sustentabilidade & $*$ Não ser novo, não saber a procedência \\
*Menor custo & *Preocupação com o estado de conservação \\
*Não se preocupar com o destino & $*$ Maior custo, riscos de contrato \\
*Economia de espaço & *Preocupação em danificar o produto \\
*Possibilidade de experimentar & $*$ Não poder customizar, fazer modificações ao móvel \\
\hline
\end{tabular}




\subsubsection{Fatores Materiais}

O destino do produto é um fator que influencia tanto negativamente quanto positivamente. Alguns consumidores, consideram a responsabilidade pelo destino do móvel um fardo, e, por conseguinte, entendem a devolução para o fabricante como um serviço prático e vantajoso, que reduz esta preocupação. Outros consideram como desvantagens do serviço as impossibilidades de: manter o móvel na família; doar para quem precisa; reutilizar o móvel em outros cômodos; ou revender.

A narrativa mais citada como vantajosa pelos respondentes foi a percepção de que o serviço é flexível e prático, e se adequa ao tempo e ao tipo de uso do mobiliário : "Uma vantagem é que não precisaremos montar o quarto por completo. Podemos ver as necessidades e alugar apenas quando for usar." (respondente $\mathrm{n}$ ㅇ 1).

A relação de custo-benefício é fator de grande influência para a aceitação. Assim como verificado por Catulli (2012), os consumidores apresentaram dúvidas quanto à relação custobenefício ou opiniões divergentes. Grande parte dos respondentes colocam que a aceitação ao serviço depende da comparação dos custos e riscos de contrato entre os dois modelos de consumo. $25 \%$ dos respondentes acreditam que o serviço seria mais vantajoso financeiramente, $16 \%$ acreditam que o aluguel tende sempre a ser mais oneroso, principalmente quando comparado ao mercado de usados (segunda-mão).

Corroborando também os resultados de Cherry e Pidgeon (2018), sobre a relevância da propriedade para a autonomia, muitas das desvantagens citadas se relacionam à redução de liberdade de uso: "limita a criatividade de pintar o móvel, por exemplo, ou colar figurinhas nele." (respondente no 15). A preocupação em danificar os objetos, principalmente em função do uso com crianças, foi recorrente entre os respondentes: "Eu fico muito preocupada com a devolução, porque eu não tenho como garantir em que condições eu vou devolver. A criança pode riscar o bercinho branco com pilot ou colar um adesivo." (respondente № 13).

Consumidores também demonstraram o desejo de ter a liberdade de fazer modificações ao mobiliário e customizá-lo a seu gosto. Ao mesmo tempo, demonstraram dúvidas quanto ao estado de conservação, segurança e higiene dos produtos. O que, do ponto de vista do consumidor, pode ser resolvido com informação sobre procedimentos de higienização e manutenção, garantias do contrato, e o próprio aspecto dos objetos.

\subsubsection{Fatores psicossociais}

Os fatores psicossociais que influenciam negativamente a adoção do serviço são, de fato, como apontados por Oliveira (2000), relacionados ao "valor simbólico de virgindade". 25\% das desvantagens levantadas tiveram relação com o fato dos objetos do serviço serem usados: "Produto vem com a energia de antigos usuários" (respondente no 62), "Antigo usuário desconhecido" (respondente no 22), "Pega cheiro" (respondente no 70). Como observado por Catulli (2012), a natureza do uso com bebês, em especial a primeira gestação, pode influenciar a aceitação do serviço : "Eu sou muito ligada em energia, então, alugar uma coisa que já passou na casa de outras pessoas talvez possa influenciar. Quando é o primeiro bebê, a gente quer tudo novo, se puder financeiramente." (respondente $n$ 으)

Alguns consumidores apreciam herdar o móvel usado de familiares ou amigos, e inclusive apreciam também a ideia de passar adiante para manter o móvel circulando na família, valorizando a história e as memórias que o objeto carrega: "Só vejo desvantagem no sentindo afetivo, como o berço construído pelo meu avô que está sendo utilizado por toda a família por gerações." (respondente no 69). O valor das marcas do objeto usado, neste sentido, passa a ser um fator que também influencia negativamente o serviço. A questão é que isto depende, 
logicamente, das circunstâncias e estrutura familiar de cada consumidor: "A vantagem vai depender da família que você tem. No caso da minha não é vantajoso, porque é grande, os móveis já foram usados por 5 crianças." (respondente $\mathrm{n}$ ㅇ 26).

Não foram identificadas nas respostas, influências relacionadas ao padrão de vida, status e identidade, no sentido colocado pelos autores pesquisados. Não surgiram comentários sobre a marca dos produtos, nem sobre a auto-imagem que o objeto alugado pode veicular. No entanto, um estilo de vida sustentável foi valorizado por $36 \%$ dos respondentes, que colocaram o valor ambiental do serviço como característica positiva e desejável: "Achei a ideia muito legal e usaria. É sustentável, se adaptaria ao que preciso, e na hora da devolução teria um destino." (respondente no 44); "Benefícios para a sociedade como um todo (reaproveitamento / menos lixo) e, suponho, economia na hora de montar o espaço." (respondente no 4); "Seria preciso comparar os preços desse sistema com a compra comum para ver se vale a pena. Mas sou super a favor do reaproveitamento e da sustentabilidade." (respondente $\mathrm{n}$ ㅇ 9).

\section{Conclusão}

Dentre os fatores materiais mais relevantes, a percepção de que o serviço se adequa ao uso e às necessidades, fornecendo praticidade ao usuário, é vista como a principal vantagem que influencia positivamente a aceitação. No entanto, o usuário precisa perceber vantagem na relação de custo-benefício do serviço ao compará-lo à compra, para aceitá-lo. Já, a responsabilidade pelo destino do produto, ao mesmo tempo em que oferece vantagem ao consumidor - que não quer a preocupação na hora de se desfazer - é vista como desvantagem pelos usuários que consideram relevante a possibilidade de doar para quem precisa e reutilizar na família ou em outros cômodos.

Foram identificados como fatores psicossociais mais relevantes: o valor simbólico do novo e o valor da sustentabilidade. Para que haja sucesso na aceitação do serviço ecoeficiente, estes entraves devem ser cuidados: contratos que possibilitem uma maior liberdade de uso, formas de informar e garantir a segurança, a manutenção e higiene do produto, que se reflita no aspecto de novo do móvel. Também a alta resposta em relação à sustentabilidade, indica que há um mercado de nicho, com expectativas e desejos por consumo sustentável. Mostra que o cuidado com o ambiente é um fator relevante, corroborando Catulli (2013).

Concluiu-se, a partir da análise dos fatores apontados pelos respondentes, que há uma atitude positiva em relação aos serviços ecoeficientes. Os serviços, no entanto, precisam se diversificar e multiplicar, para que sejam testados e avaliados e dessa forma ganhar visibilidade.

Considerou-se importante para o desdobramento desta pesquisa, ampliar quantitativamente e diversificar a amostra, para validar a existência de um nicho para o consumo de serviços ecoeficientes.

\section{Referências}

BARDHI, F.; ECKHARDT, G. M. Access-based consumption: The case of car sharing. Journal of consumer research, v. 39, n. 4, p. 881-898, 2012. Disponível em: <https://academic.oup.com/ jcr/article/39/4/881/1798309> Acesso em: 27 set. 2018.

BEHRENDT, S. et al. Eco-service Development : Reinventing Supply and Demand in the European Union. Sheffield: Routledge, 2003. Disponível em: <http://search.ebscohost.com/login.aspx?direct $=$ true $\& d b=$ lebk\&AN=561550\&lang=pt-br\&site=eds-live \&scope=site $>$. Acesso em: 30 jul. 2018.

BOTSMAN, R.; ROGERS, R. 0 que é meu é seu: como o consumo colaborativo vai mudar o nosso mundo. Porto Alegre: Bookman, 2011.

BREZET, J. C. et al. The design of eco-efficient services. Methods, tools and review of the case 
study based "Designing eco-efficent Services" project. Design for Sustainability Program, Delft University of Technology, 2001. Disponível em: <https://www.researchgate.net/publication/ 31305432 _The_Design_of_Eco-Efficient_Services> Acesso em: 30 jul. 2018

CATULLI, M. What uncertainty? Further insight into why consumers might be distrustful of product service systems. Journal of Manufacturing Technology Management, v. 23, n. 6, p. 780-793, 2012. Disponível em: <https://uhra.herts.ac.uk/handle/2299/8995/restricted-resource?bitstreamld=348 05> Acesso em: 30 jul. 2018

CATULLI, M. et al. What is Mine is NOT Yours: Further insight on what access-based consumption says about consumers. In: Consumer culture theory. Emerald Group Publishing Limited, 2013. p. 185-208. Disponível em: <https://uhra.herts.ac.uk/dspace/handle/2299/5549>Acesso em:jul. 2018

CHERRY, C.; PIDGEON, N. Why Is Ownership an Issue? Exploring Factors That Determine Public Acceptance of Product-Service Systems. Sustainability, v. 10, n. 7, 2289, Jul. 2018. Disponível em: < https://www.mdpi.com/2071-1050/10/7/2289> Acesso em: 27 set. 2018

GUATTARI, F. As três ecologias. Campinas: Papirus, 1990.

MANZINI, E. Design para a inovação social e sustentabilidade: comunidades criativas, organizações colaborativas e novas redes projetuais. Rio de Janeiro: E-papers, 2008.

MEIJKAMP, R. Changing consumer behaviour through eco-efficient services: an empirical study of car sharing in the Netherlands. Business Strategy \& the Environment (John Wiley \& Sons, Inc), v. 7, n. 4, p. 234-244, sept. 1998.

MOELLER, S.; WITTKOWSKI, K. The burdens of ownership: reasons for preferring renting. Managing Service Quality: An International Journal, v. 20, n. 2, p. 176-191, 2010.

MONT, O. Clarifying the concept of product-service system. Journal of cleaner production, v. 10, n. 3, p. 237-245, 2002.

MONT, O.; PLEPYS, A. Customer satisfaction: review of literature and application to the productservice systems. International Institute for Industrial Environmental Economics at Lund University, 2003. Disponível em: https://www.researchgate.net> Acesso em: mar 2018

MONT, O. et al. A new business model for baby prams based on leasing and product remanufacturing. Journal of Cleaner Production, v. 14, n. 17, p. 1509-1518, 2006.

OLIVEIRA, A. J. de. Eco-design e remanufatura: algumas contribuições para o projeto de produtos eco-eficientes. 2000. 253 p. Tese (Doutorado em Ciências em engenharia de Produção), COPPE/UFRJ, Rio de Janeiro, 2000.

SANTOS, A. dos. Níveis de maturidade do design sustentável na dimensão ambiental. In: MORAES, D.; KRUCKEN, L. (org.) Cadernos de Estudos Avançados em Design: Design e Sustentabilidade I. 2. ed. Barbacena: EdUEMG, v.3, p. 19 -32, 2003.

SCHRADER, U. Consumer acceptance of eco-efficient services. Greener Management International, n. 25, p. 105-121, 1999.

STAHEL, W. The performance economy. 2nd ed. Springer, 2010. Disponível em: <https://www.glo be-eu.org/wp-content/uploads/THE_PERFORMANCE _ ECONOMY1. pdf> Acesso em: set. 2018

TUKKER, A. Eight types of product-service system: eight ways to sustainability? Experiences from SusProNet. Business strategy and the environment, v. 13, n. 4, p. 246-260, 2004.

VEZZOLI, C. et al. Sistema produto + serviço sustentável: fundamentos. Curitiba: Insight, 2018. Disponível em : <http://editorainsight.com.br/wp-content/uploads/2018/03/aSistema-Produto Servico -Sustentavel_web.pdf> Acesso em : 26 jun. 2018 